\title{
Research on Inductance Converter Based on IGBT for Dynamic Reactive Power Compensation Device
}

\author{
Ziwei WANG ${ }^{\mathrm{a}}$, Youxin YUAN $^{\mathrm{b}}$, Jing $\mathrm{CHEN}^{\mathrm{c}}$ \\ School of Automation, Wuhan University of Technology, Wuhan, 430070, China \\ aemail:504521379@qq.com, bemail:yyx2000@263.net, cemail:jingchen680@163.com
}

Keywords: Inductance Converter; Reactive Power Compensator; Dynamic Compensation.

\begin{abstract}
In power system, a large number of the inductive loads need the reactive power. These loads always make dramatic voltage fluctuation in power system. The traditional static reactive power compensator is difficult to meet the needs of the adjustable reactive power capacity .Therefore, a dynamic reactive power compensation method of the inductance converter based on IGBT is proposed in this paper. The following works have been done in the study: research of the inductance converter based on IGBT, modeling and simulation with MATLAB/SIMULINK, and its application in a dynamic reactive power compensation device. The hardware and software designs are realized in this paper, and it is subsequently verified experimentally. Experimental results show that inductance converter based on IGBT can be applied effectively in dynamic reactive power compensation.
\end{abstract}

\section{Introduction}

In power system, a large number of the inductive loads need the reactive power [1] [2]. The lack of energy and resources are increased, so that energy conservation has become a more serious issue. In order to effectively improve the utilization rate of energy, reactive power compensation plays an important role. But traditional static reactive power compensator is difficult to meet the needs of the adjustable reactive power capacity [3]. With the development of power electronic element, they are applied widely in inductance converter.

Though, authors have advocated the use of inductance converter based on SCR for dynamic reactive power compensation [4]. Compared with SCR, IGBT is characterized by high reliability, fast switching speed and extensive applicability. So, the reactive power can be smoothly adjusted to achieve dynamic reactive power compensation.

Therefore, inductance converter based on IGBT is researched in this paper. It is composed of inductance converter and electronic power inverter. The following works have been done in the study: research of inductance converter based on IGBT, modeling and simulation with MATLAB/SIMULINK, and its application in dynamic reactive power compensation.

\section{Topological Structure and Transforming Mechanism of Inductance Converter Based on IGBT}

The topological structure of inductance converter is shown in Fig.1. Single-phase inductance converter is taken as an example to analyze the transforming mechanism [5].

In following formulas, $\mathrm{u}_{1}, \mathrm{U}_{1}, \mathrm{U}_{1 \mathrm{~m}}$ are respectively the voltage of the primary side, the effective value of the voltage and the maximum value of the voltage of the primary side. Likewise, $\mathrm{u}_{2}, \mathrm{U}_{2}$, $\mathrm{U}_{2 \mathrm{~m}}$ are respectively the voltage of the primary side, the effective value of the voltage and the maximum value of the voltage of the second side. $K$ is the ratio of $L_{1}$ to $L_{2}$.

Let $f=\left\{\begin{array}{llll}1 & I G B T_{2} & \text { positive conductio or } I G B T_{1} & \text { reverse conduction } \\ 0 & I G T B_{2} & \text { positive cutoff or } I G B T_{1} & \text { reverse cutoff }\end{array}\right.$

The Fourier series expansion is given by Eq.1, where D is the duty-cycle of PWM wave.

$$
f=D+\frac{2}{\pi} \sum_{n=1}^{\infty} \frac{F(D, k)}{n} \cos n \omega t
$$




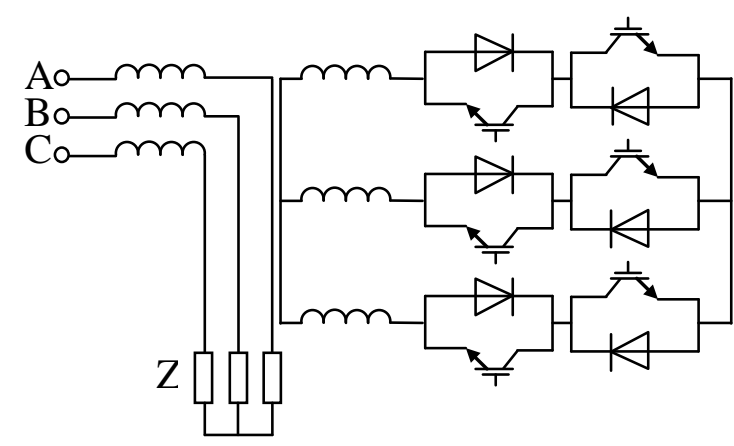

(a) Single-phase inductance converter based on IGBT

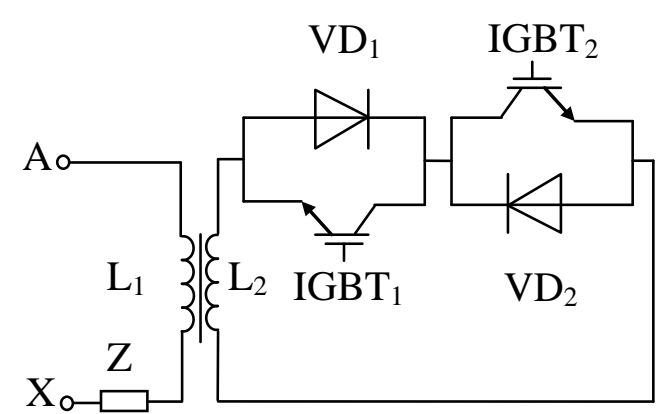

(b) Three-phase inductance converter based on IGBT

Fig.1. The topological structure of inductance converter based on IGBT

$$
\begin{aligned}
& F(D, \mathrm{k})=\sin \frac{2 n \pi}{k} D+\sin \left(\frac{2 n \pi}{k}+\frac{2 n \pi}{k} D\right)-\sin \frac{2 n \pi}{k}+\left(\frac{4 n \pi}{k}+\frac{2 n \pi}{k} D\right)-\sin \frac{4 n \pi}{k}+\ldots \\
& +\sin \left(\frac{k-2}{2} \cdot \frac{2 n \pi}{k}+\frac{2 n \pi}{k} D\right)-\sin \left(\frac{k-2}{2} \cdot \frac{2 n \pi}{k}\right)
\end{aligned}
$$

Higher harmonic can be inhibited by inductance in the second side circuit. Here, only fundamental wave should be considered.

$$
\begin{aligned}
& U_{2}=f U_{2 m} \sin \omega t \approx D U_{2 m} \sin \omega t \\
& i_{2}=\frac{U_{2}}{Z_{2}}=\frac{D U_{2 m} \sin \left(\omega t-\varphi_{1}\right)}{Z_{2}} \\
& i_{1}=\frac{D U_{1 m} \sin \left(\omega t-\varphi_{1}\right)}{K^{2} Z_{2}}
\end{aligned}
$$

The equivalent reactance of the variable reactor $\mathrm{Z}$ is as follows:

$$
\begin{aligned}
& |Z|=\frac{U_{1}}{I_{1}}=\frac{K^{2} Z_{2}}{D} \\
& Z=R+j \omega L
\end{aligned}
$$

It can be proved that the change of D, the duty-cycle of PWM wave, can result in the change of the equivalent reactance of inductance converter in the analysis above.

\section{Simulation of Inductance Converter Based on the IGBT}

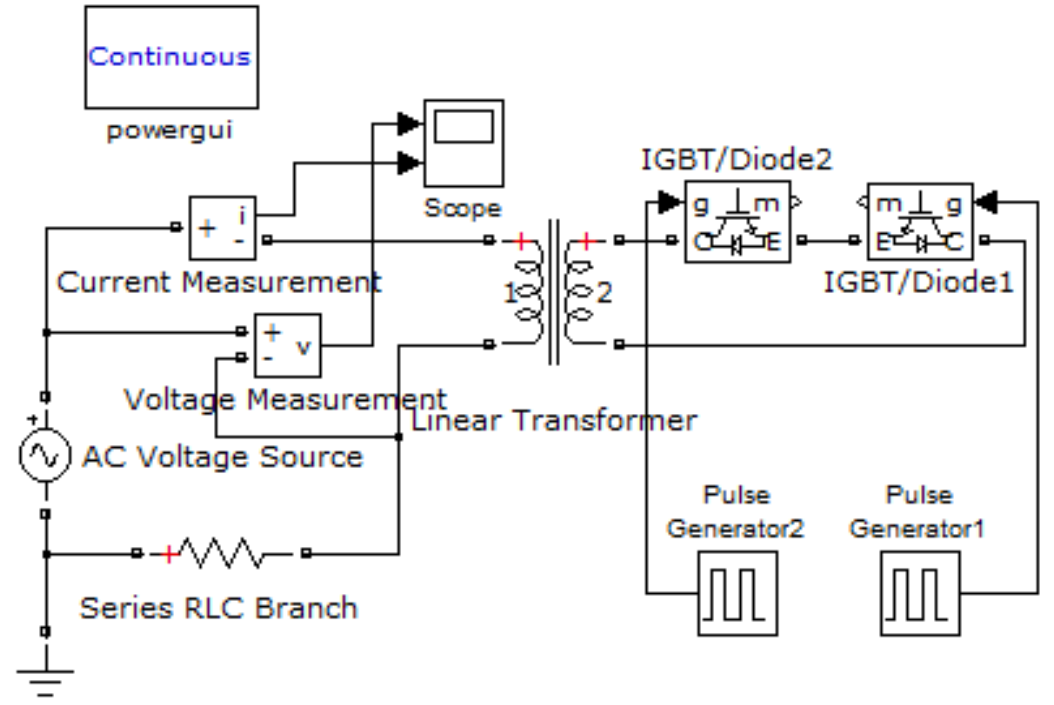

Table 1. Simulation parameters

\begin{tabular}{c|c}
\hline $\begin{array}{c}\text { AC voltage } \\
\text { source }\end{array}$ & $50 \mathrm{~Hz} / 220 \mathrm{~V}$ \\
\hline $\mathrm{U}_{1}$ & $50 \mathrm{~Hz} / 220 \mathrm{~V}$ \\
\hline $\mathrm{R}_{1}(\mathrm{pu})$ & 0.622 \\
\hline $\mathrm{L}_{1}(\mathrm{pu})$ & 0.079 \\
\hline $\mathrm{U}_{2}$ & $50 \mathrm{~Hz} / 110 \mathrm{~V}$ \\
\hline $\mathrm{R}_{2}(\mathrm{pu})$ & 0.622 \\
\hline $\mathrm{L}_{2}(\mathrm{pu})$ & 0.079 \\
\hline $\mathrm{Rm}(\mathrm{pu})$ & 155500 \\
\hline $\mathrm{Lm}(\mathrm{pu})$ & 435 \\
\hline
\end{tabular}

Fig.2. The simulation model of inductance converter based on the IGBT

On the basis of the topological structure of inductance converter based on IGBT, the simulation 
model is shown in the Fig. 2. Simulation parameters are set up as shown in the table 1. Frequency of all should be set up as $50 \mathrm{~Hz}$. The simulation algorithm is obt23tb and the simulation time is $15 \mathrm{~s}$.

The result of the simulation is shown in Table 2.According to Table1, the relationship between the $\mathrm{Z}$ and $\mathrm{D}$ can be presented in the curve shown in Fig.3.it comes to the conclusion that the result mentioned above can be confirmed.

Table 2. The result of the simulation

\begin{tabular}{c|c|c|c}
\hline $\mathrm{D}$ & $\mathrm{U}_{1}(\mathrm{~V})$ & $\mathrm{I}_{1}(\mathrm{~A})$ & $\mathrm{Z}(\Omega)$ \\
\hline $5 \%$ & 220.000 & 0.0805 & 2732.919 \\
\hline $10 \%$ & 219.425 & 0.1870 & 1173.396 \\
\hline $15 \%$ & 219.850 & 0.2751 & 799.164 \\
\hline $20 \%$ & 220.023 & 0.3375 & 651.919 \\
\hline $25 \%$ & 223.320 & 0.3665 & 609.331 \\
\hline $30 \%$ & 208.130 & 0.3665 & 567.885 \\
\hline $35 \%$ & 173.050 & 0.3648 & 474.435 \\
\hline $40 \%$ & 150.100 & 0.3669 & 409.103 \\
\hline $45 \%$ & 147.150 & 0.3650 & 403.151 \\
\hline $50 \%$ & 145.950 & 0.3625 & 402.620 \\
\hline
\end{tabular}

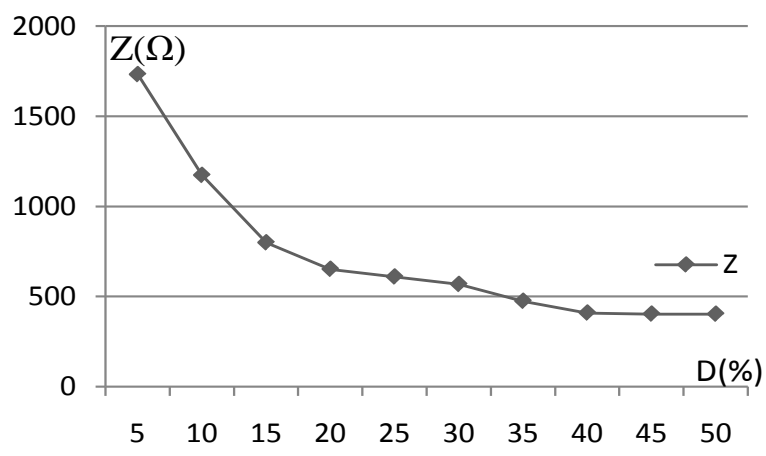

Fig.3. The curve of the relationship between the $\mathrm{Z}$ and $\mathrm{D}$

\section{Application of Inductance Converter Based on IGBT in the Dynamic Reactive Power Compensation}

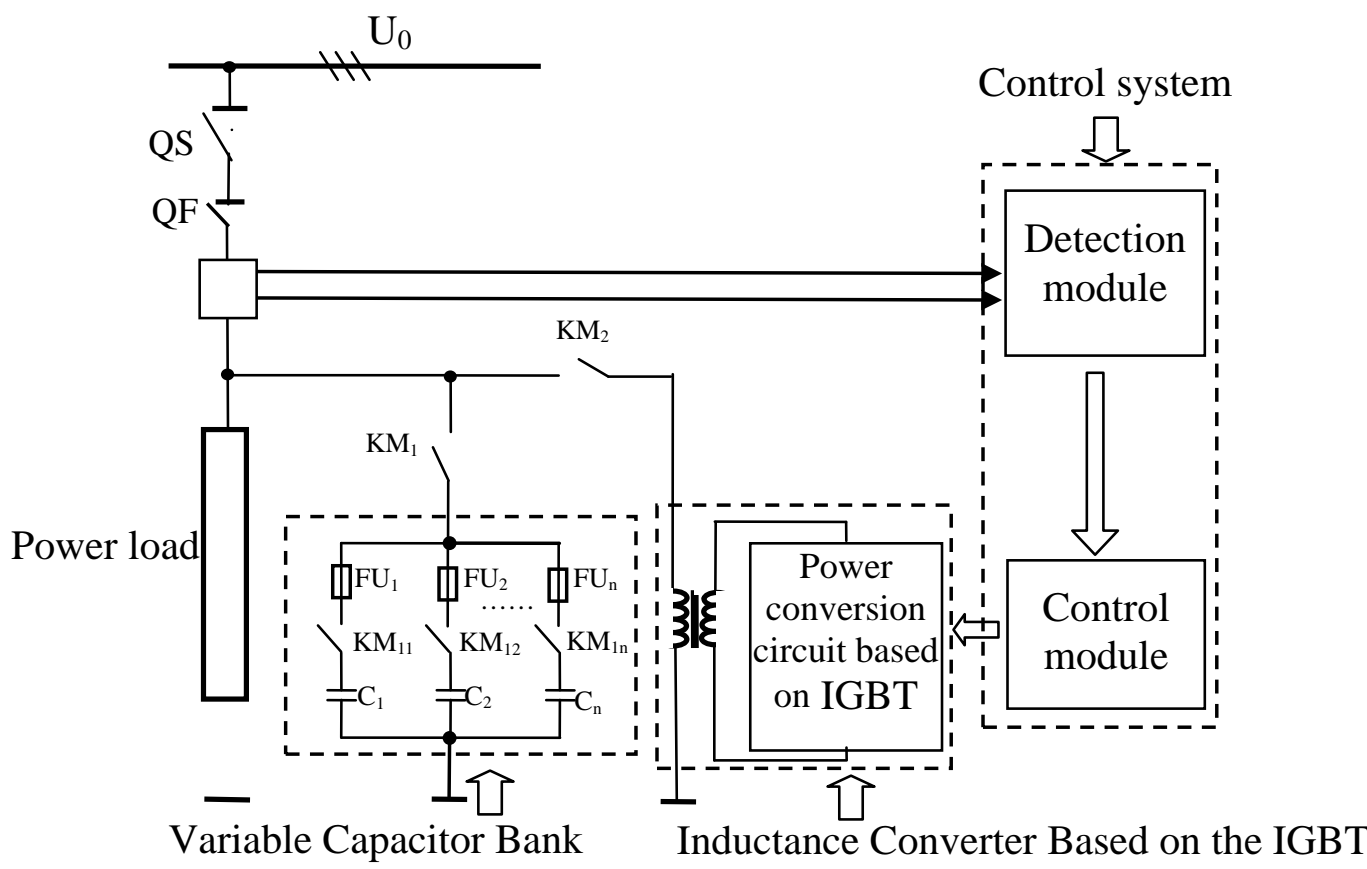

Fig.4. The topological structure of the dynamic reactive power compensator

In power system, there is a large number of reactive power consumption. The inductance converter and the capacitor bank can be connected in parallel as the dynamic reactive power compensator. Its topological structure is shown in Fig.4. The dynamic reactive power compensation device consists of the following three units. They are the capacitor banks, the inductance converter, and control system [6]. In Fig.4, QS is the high-voltage isolation switch; QF is the high-voltage circuit breaker; $\mathrm{KM}_{1}, \mathrm{KM}_{2}$ are high voltage connectors; the capacitor bank is consists of capacitor $\mathrm{C}_{1-\mathrm{n}}$, high voltage connectors $\mathrm{KM}_{11-1 \mathrm{n}}$, and High voltage fuse $\mathrm{FU}_{1-\mathrm{n}}$. 


$$
\begin{aligned}
& Q=Q_{C}+Q_{L} \\
& Z=Z_{C} / / Z_{L}
\end{aligned}
$$

Taking the advantage of the reactance conversion mechanism and the capacitor bank , the reactive power can be compensated. When the power factors of circuitry changes, adjusting the duty-cycle of PWM wave D and the method of capacitance sets switched to compensate, so as to improve the power factor, and reach the aim of energy-saving.

\section{Summary}

In power system, there are a lot of reactive power consumptions. Many adverse effects are always made by nonlinear devices, and dramatic voltage fluctuations can be caused, such as lower power factor and power loss. For this case, it's of great significance to research the active device to solve these problems. Therefore, the application of inductance converter based on IGBT in dynamic reactive power compensator is proposed in this paper.

The following works have been done in the study: research of inductance converter based on the IGBT, modeling and simulation with MATLAB/SIMULINK, and its application in dynamic reactive power compensator. When the inductance converter is cooperated with the capacitor bank, the dynamic reactive power compensator can realize the fast and smooth reactive power compensation.

\section{Acknowledgements}

This work was financially supported by the projects of Hubei Science and Technology Plans of China (Granted No: 2013BAA009).

\section{References}

[1] Yongzhong Ding, Yoxin Yuan, Yiping Xiao, Xufang Zhang, and Kaihua Cui. Research on Variable Reactor Based on Power Convert [J]. Journal of Wuhan University of Technology, 200830 (3) 136-138.

[2] Youxin Yuan, Shanshan Cai, Quanju Ban, Tanfu Xiao, and Tieliang Xu. Research on Topology of the Static Reactive Power Compensator Based on the Controlled Reactance [J]. Journal of Wuhan University of Technology, 200931 (12) 120-122.

[3] Da Lu, Benguo Liu, and Gang Quan. Typical Control Principle and Control Method and Analysis of Thyristor Controlled Reactor (TCR) [J]. Power System Technology, 199721 (3) 25-27.

[4] Yufang Chang, Youxin Yuan, Wencong Huang, and Yan Xu. Research on Impedance Conversion of Power Electronic Reactor [J]. Journal of Wuhan University of Technology, 2011 33 (10) 127-130.

[5] Yufang Chang, Youxin Yuan, Yan Xu, and Wencong Huang. Topological Structure and Impedance Conversion Analysis of Power Electronic Reactor [J]. Power Electronics, 201246 (2) 21-23.

[6] Na Xie, Youxin Yuan, Xianglian Xu, Hongming Hu, and Yiping Xiao. Research on static reactive power compensator Mechanism of Compensation Based on Variable Reactor [J]. Journal of Wuhan University of Technology, 201032 (10) 129-132. 